SVU- International Journal of Veterinary Sciences, 4 (2): 35-50, 2021.

Print ISSN: 2535-1826

\title{
L-arginine pre-treatment ameliorates Lipopolysaccharide-induced thyroid gland dysfunction in male albino rats
}

\author{
Basma Osama ${ }^{1 *}$, Hamdy M. Embark ${ }^{2}$
}

${ }^{1}$ Animal Physiology Department, Faculty of Veterinary Medicine, Aswan University, Aswan 81528, Egypt, ${ }^{2}$ Animal Physiology Department, Faculty of Veterinary Medicine, South Valley University, Qena 83523, Egypt

\section{Abstract}

Bacterial infection is one of the most common causes of systemic inflammatory syndrome known as sepsis. Previous studies have been shown that sever sepsis was often complicated with secondary multiple organs dysfunction. This syndrome may greatly affect thyroid gland function leading to thyroid gland dysfunction. The objective of this study was to elucidate the effect of bacterial endotoxin (lipopolysaccharide, LPS) on thyroid gland function. The study extended to investigate the role of L-arginine (L-Arg) as immunomodulator in LPS-induced systemic inflammation. Eighty adults, male Wistar rats were randomly divided into four equal groups: The control group was intraperitoneally (IP) injected with physiological sterile saline $(0.9 \% \mathrm{NaCl}$ at dose $1 \mathrm{ml} / \mathrm{kg}$ body weight (BW)); LPS-treated group was injected with a single dose of LPS (1 mg/kg BW, IP); L-Argtreated group was injected with L-Arg $(10 \mathrm{mg} / \mathrm{kg} \mathrm{BW}$, IP) once per day for 7 consecutive days; and L-Arg + LPS treated group was injected with L-Arg $(10 \mathrm{mg} / \mathrm{kg} \mathrm{BW}$, IP) once per day for 7 consecutive days followed by a single dose of LPS (1 mg/kg BW, IP). Histopathological changes of thyroid gland, serum triiodothyronine (T3), thyroxine(T4), and thyroid stimulating hormone (TSH) levels were examined at 6,12, 24 and 72 hours (h) after the last injection. Treatment of rats with a single dose of LPS alone resulted in thyroiditis which manifested by decreased serum T3 and T4 levels and severe necrosis of the thyroid follicles. However, in L-Arg-treated endotoxemic rats, pretreatment with L-Arg attenuated the LPS-induced acute thyroid gland injury.

Keywords: L-arginine, Lipopolysaccharide, T3, T4, TSH.

DOI: 10.21608/svu.2021.60533.1104 Received: January 31, 2021 Accepted: May 21, 2021

Published: May 29, $2021{ }^{*}$ Corresponding Author: Basma Osama E-mail: basma_osama@vet.aswu.edu.eg

Citation: Osama and Embark: L-arginine pretreatment ameliorates Lipopolysaccharide-induced thyroid gland dysfunction in male albino rats. SVU-IJVS 2021, 4 (2): 35-50.

Copyright: () Osama and Embark. This is an open access article distributed under the terms of the creative common attribution license, which permits unrestricted use, distribution and reproduction in any medium provided the original author and source are created.

Competing interest: The authors have declared that no competing interest exists.

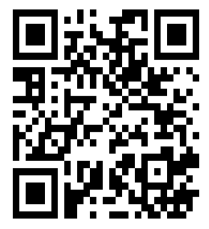




\section{INTRODUCTION}

Lipopolysaccharide (LPS) is a bacterial endotoxin of the outer layer of cell wall of Gram-negative bacteria which can induce cytokines synthesis and inflammatory response in the body (Chen et al., 2018). Toll-like receptors (TLRs) are germline-encoded receptors which found in the cell membrane of immune cells such as monocytes, macrophages, dendritic cells, and B cells. Toll-like receptor 4 (TLR4) is the major receptor for LPS recognition (Akira et al., 2006).

L-arginine (L-Arg) is semi-essential natural amino acid that was discovered by Hedin in 1895 as a natural amino acid protein. L-Arg is responsible for several biological functions such ammonia detoxification, regulation of blood pressure, modulation of immune responses, and maintaining endocrine functions (Kopincová et al., 2012). Moreover, it is used as substrate for synthesis of proteins, urea, polyamines, proline, glutamate, creatine, and agmatine (Mc Conell, 2007).

It is hypothesized that pretreatment with L-Arg, may be ameliorating the thyroid gland dysfunction induced by LPS. Therefore, in the present study, intraperitoneal injection of LPS and/or LArg were used to investigate the effect of L-Arg on LPS-induced systemic inflammation, thyroiditis, and thyroid injury in adult male rats.

\section{MATERIALS AND METHODS}

\section{Ethical Approval}

The animal experimental protocols were approved by the Animal Care and Use Committee of the South Valley University. All efforts were made to minimize animal suffering and to reduce their number, in accordance with the Egypt National Institutes of Health Guidelines for the Care and Use of Laboratory Animals. The animals were examined and adapted to the new environmental conditions for a week before the formal experiment.

\section{Experimental animals}

The experiments were carried out on eighty healthy adult male Wistar albino rats, weighing 250-310 g. Rats were procured from the laboratory animal house, Faculty of Medicine, Assiut University, Assiut and transferred to the animal house, Physiology Department, Faculty of Veterinary Medicine, South Valley University, Qena. They were kept at a temperature of about $26 \pm 2^{\circ} \mathrm{C}$ with $60 \%$ relative humidity under a $12 \mathrm{~h}$ alternating light-dark cycle. Rats were received food and water ad libitum and divided into four equal groups $(n=20$ per group) in which each experimental group was subdivided into four replicates of five rats.

\section{Drugs and Chemicals}

Lipopolysaccharide (LPS) from Escherichia coli (E. coli, O111:B4 serotype) and L-arginine (L-Arg) were obtained from Sigma Chemical Company (St Louis, MO, USA). LPS and L-Arg injections were daily freshly prepared by dissolving into a sterile, pyrogenic-free saline $(0.9 \% \mathrm{NaCl})$ and injected at a dose of $1 \mathrm{mg} / \mathrm{kg}$ and $10 \mathrm{mg} / \mathrm{kg}$ body weight (BW), respectively, (Huang et al., 2007 and Moustafa et al., 2015).

\section{Experimental Design}

After a week of acclimatization, the rats were treated as following: Group I (control): animals were intraperitoneally (IP) injected with saline $(0.9 \% \mathrm{NaCl})$ at dose $1 \mathrm{ml} / \mathrm{kg} \mathrm{BW}$. Group II (LPS-treated): animals were IP injected with a single dose of LPS (1 mg/kg BW). Group III (L-Argtreated group): rats were injected with LArg (10 mg/kg BW, IP) once per day for 7 
consecutive days. Group IV (L-Arg + LPStreated group): rats were injected with LArg (10 mg/kg BW, IP) once per day for 7 consecutive days followed by a single dose of LPS (1 mg/kg BW, IP). All the injections were performed in the morning at 8:00 am.

\section{Clinical signs and mortality observations}

Clinical signs and mortality rate of all treated rats were recorded according to the timetable of experiment $(6,12,24$, and 72 hours (h)) from the last injection.

\section{Recording of daily food and water intake}

Every day, the food and water intake were recorded for one subgroup of each group (cage continued for $72 \mathrm{~h}$ ) at 8:00 am after last injection in different treated groups.

\section{Measurement of body weight gains}

Body weights were recorded for all treated animals once daily throughout the study period during the light period beginning at 8:00 am prior to the feeding of the experimental diets. The body weight gain (g/day) was calculated as follows: Weight gain $(\mathrm{g} /$ day $)=\mathrm{W} 2-\mathrm{W} 1$

Where, $\mathrm{W} 1=$ initial weight; and $\mathrm{W} 2=$ final weight of the same rat, in $\mathrm{g}$

\section{Samples Collection}

Blood samples were collected from retro-orbital venous plexus before sacrificing from each subgroup 6, 12, 24 and $72 \mathrm{~h}$ after the last injection in test tubes without anticoagulant. Serum samples were separated by centrifugation at $3000 \mathrm{rpm}$ for 15 minutes and collected in Eppendorf tubes. Sera were stored at $-80^{\circ} \mathrm{C}$ until assay of serum levels of triiodothyronine (T3), thyroxin (T4), and thyroid stimulating hormone (TSH). Rats were anesthetized with sodium thiopental $(50 \mathrm{mg} / \mathrm{kg} \mathrm{BW}, \mathrm{IP})$ (Mammadov et al., 2019), sacrificed, and thyroid glands were collected for histopathological examination.

\section{Measurement of thyroid function parameters}

The frozen sera were thawed and serum $\mathrm{T} 3$, T4, and TSH levels were measured using enzyme-linked immunosorbent assay (ELISA) kits according to manufacturer's instructions (Calbiotech, El Cajan, CA, USA). Absorbance at $450 \mathrm{~nm}$ was measured using the Tecan Infinite M1000 Pro microplate reader with Magellan data analysis software (Tecan Systems, Inc.). All samples and standards were measured in duplicate.

\section{Histopathology examination}

Thyroid gland samples of all rats in the experimental groups were removed and fixed immediately in $4 \%$ neutral buffered paraformaldehyde (PFA) processed through the conventional paraffin embedding technique (Bancroft and Gamble, 2002). Paraffin blocks were sectioned into $5 \mu \mathrm{m}$ thick sections and stained with Haematoxylin and Eosin (H\&E) (Harris, 1900). All thyroid gland sections were observed under a light microscope.

\section{Statistical Analysis}

The results were statistically analyzed using Graph pad prism 5 and Excel 2010 software with significance level of $\mathrm{P}<0.05$. Data were presented as mean \pm standard error of mean (SEM) and compared by using Student's t-test.

\section{RESULTS}

\section{Clinical signs}

In this study, infusion of sublethal dose of the bacterial endotoxin (lipopolysaccharide, LPS) in healthy adult male Wister rats resulted in an acute systemic inflammation manifested by fever, 
shivering, reduced activity, ruffled fur, anorexia, and lethargy. These signs were temporary, persisted for a few hours (h) after injection, and disappeared over the time in our experimental rat model. As expected, control and L-arginine (L-Arg) groups showed no clinical signs of inflammation. In the other hand, L-Arg pretreated LPS rats showed the same clinical signs observed in LPS alone injected animals.

\section{Survival rate}

The survival rate of rats in LPS-treated group was $90 \%$ after 3 days of LPS injection. In contrast, animals injected with saline or L-Arg alone did not present any death, where the survival rates were $100 \%$ during the 3 days. However, the survival rate of rats in L-Arg + LPS-treated group was $85 \%$ during the last 3 days of the last injections (Fig. 1).

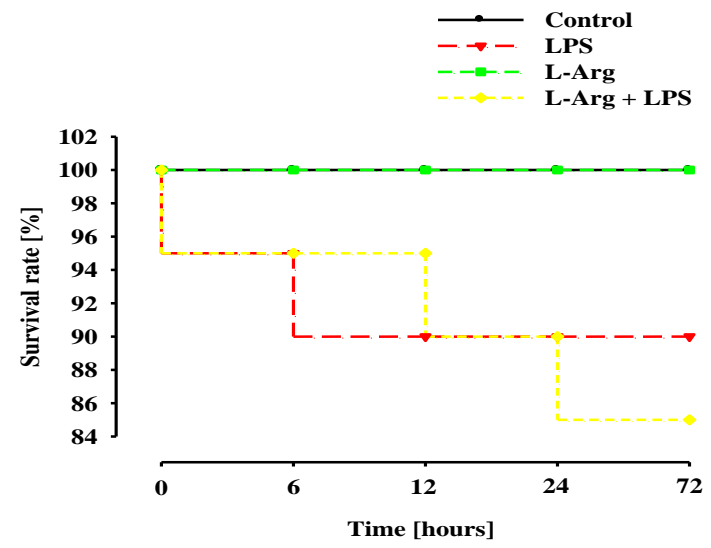

Fig. 1. The survival rate of rats at different time points. In: Control, LPS-treated (LPS), L-Argtreated (L-Arg) and L-Arg-pretreated with LPS (LArg + LPS) groups. Values expressed as a percentage $(\%)$ of rats alive compared with the initial group $(\mathrm{n}=20)$.

\section{Food consumption}

Fig. 2 shows the results of food intake ( $\mathrm{g} / 100 \mathrm{~g}$ body weight (BW)) on 1st, 2nd and 3rd days after the last injection in all experimental groups.

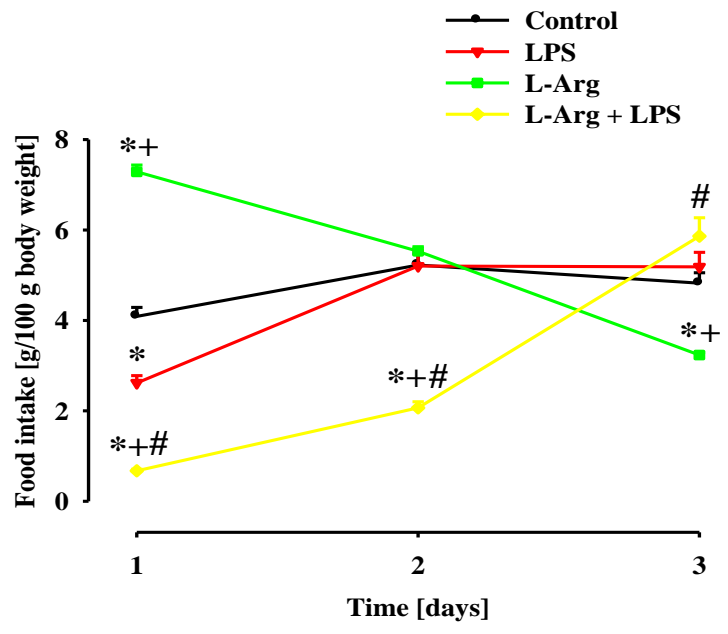

Fig. 2. Food intake (g/100 $\mathrm{g} \mathrm{BW}$ ) of rats at 13 days after the last injection. In: Control, LPStreated (LPS), L-Arg-treated (L-Arg) and L-Argpretreated with LPS (L-Arg + LPS) groups. Data are presented as the mean $\pm \operatorname{SEM}(n=3-5$ per treatment, independent t-test) $* \mathrm{P}<0.05$ vs. Control, $+\mathrm{P}<0.05$ vs. LPS, and \#P<0.05 vs. L-Arg groups.

Intraperitoneal(IP) injection of a single dose of LPS alone significantly reduced the food intake $(2.62 \pm 0.16)$ after 1 day of endotoxemia compared with control (4.09 \pm 0.20$)$, which recovered in 2-3 days after LPS injection $(5.20 \pm 0.34$ and $5.18 \pm 0.32$ ) and reached almost control values $(5.22 \pm 0.25$ and $4.82 \pm 0.23)$, respectively. In contrast, pretreatment with L-Arg for 7 consecutive days induced a significant increase in the food intake (7.29 \pm 0.15$)$ after 1 day of injection, which gradually decreased $(5.53 \pm 0.10)$ near to control value after 2 days of injection and significantly decreased $(3.23 \pm 0.06) 3$ days after last injection compared with control. An IP injection of L-Arg for 7 consecutive days followed by a single dose of LPS produced significant reduction food intake $(0.67 \pm 0.04$ and $2.06 \pm 0.14)$ compared to control (4.09 \pm 0.20 and 5.22 \pm 0.25$)$, L-Arg treated group $(7.27 \pm 0.15$ and $5.52 \pm 0.10)$ and LPS-treated group treated $(2.62 \pm 0.16$ and 5.20 \pm 0.34 ) 1-2 days after injections, respectively, which recovered and reached a higher value $(5.86 \pm 0.41)$ than control 
$(4.82 \pm 0.23)$ at the third day of LPS injection and significantly increased compared with L-Arg treated group (3.23 \pm 0.06$)$.

\section{Water consumption}

Fig. 3 outlines the results of water intake (mL/100 $\mathrm{g} \mathrm{BW}$ ) 1-3 days after the last injection in all experimental groups. Treatment with LPS did not modify water intake in LPS-treated rats $(9.28 \pm 0.58$ and $13.21 \pm 0.85)$ at $1-2$ days, respectively, when compared with the control rats $(9.87 \pm 0.48$ and $11.84 \pm 0.57)$. However, water intake of the same group significantly decreased (10.28 \pm 0.64$) 3$ days after LPS injection compared with the control rats (12.40 \pm 0.59$)$. On the contrary, IP injection of L-Arg daily for 7 consecutive days followed by a single dose of sterile normal saline significantly increased water intake in L-Arg-treated group (12.04 \pm 0.25$)$ one day after saline administration when compared with control group $(9.87 \pm 0.48)$.

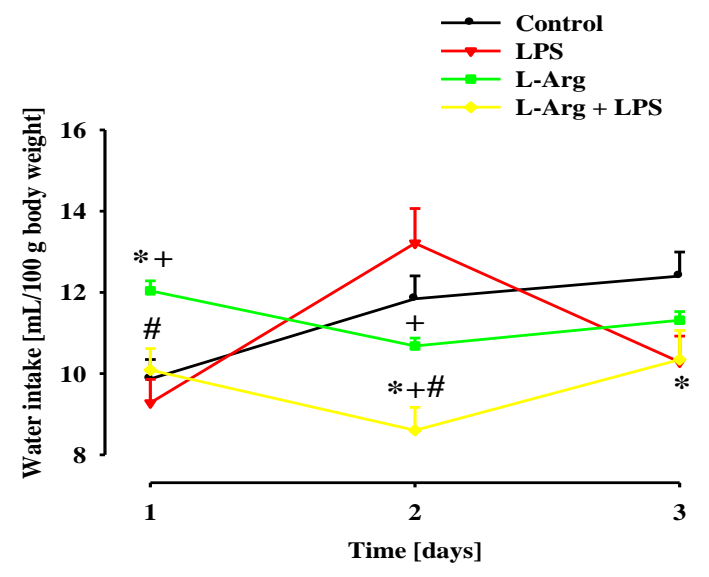

Fig. 3. Water intake (mL/100 g body weight) 1 st, 2nd, and 3rd days after last injection. In: Control, LPS-treated (LPS), L-Arg-treated (L-Arg), and LArg-pretreated with LPS (L-Arg + LPS) groups. Data are presented as the mean \pm SEM $(n=3-5$ per treatment, independent t-test) $* \mathrm{P}<0.05$ vs. Control, $+\mathrm{P}<0.05$ vs. LPS, and \#P< 0.05 vs. L-Arg groups.

The effects of L-Arg pretreatment in LArg-treated rats were transient: there was no difference in water intake between L-Argtreated $(10.68 \pm 0.20$ and $11.31 \pm 0.21)$ or control (11.84 \pm 0.57 and $12.40 \pm 0.59)$ rats at 2-3 days, respectively. In L-Arg + LPStreated group almost, there was no change in water intake between LPS + L-Argtreated $(10.09 \pm 0.53$ and $10.34 \pm 0.72)$ or control $(9.87 \pm 0.48$ and $12.40 \pm 0.59)$ rats on days 1 and 3, respectively. However, pretreatment with L-Arg significantly decreased water intake in L-Arg + LPS treated rats $(8.60 \pm 0.57)$ two day after LPS administration when compared with control rats $(11.84 \pm 0.57)$.

\section{Body weight gain}

Fig. 4 summarizes the results of daily changes in the body weight gain (g/day) of rats 1-3 days after the last injection in all experimental groups. Body weight gain of LPS-treated group did not modify $(-10.50 \pm$ 4.43) in 1 day after treatment compared with control $(-3.00 \pm 1.26)$, which reached values $(6.75 \pm 1.65)$ higher than control (3.40 \pm 1.03$)$ after 2 days of LPS injection, then decreased $(0.75 \pm 1.25)$ compared with control (3.20 \pm 0.80$)$ after 3 days injection, respectively. Conversely, body weight gain of L-Arg-treated rats significantly increased $(6.40 \pm 1.75)$ one day after the last injection compared to control rats $(-3.00 \pm 1.26)$, which recovered $(3.60 \pm 1.17)$ and reached almost control values $(3.40 \pm 1.03) 2$ days of the last injection. L-Arg-treated rats showed significant decrease of body weight gain ($10.13 \pm 1.67)$ compared to control rats $(3.20 \pm 0.80)$ at the $3 n d$ day of the last injection. Body weight gain of L-Arg + LPS group did not change (-6.67 \pm 3.76 and $0.33 \pm 0.88)$ compared with control group ($3.00 \pm 1.26$ and $3.20 \pm 0.80)$ one and three days after the last injection. However, body weight gain of L-Arg + LPS group significantly decreased $(-6.00 \pm 3.79)$ compared with control group $(3.40 \pm 1.03) 2$ days after the last injection. 


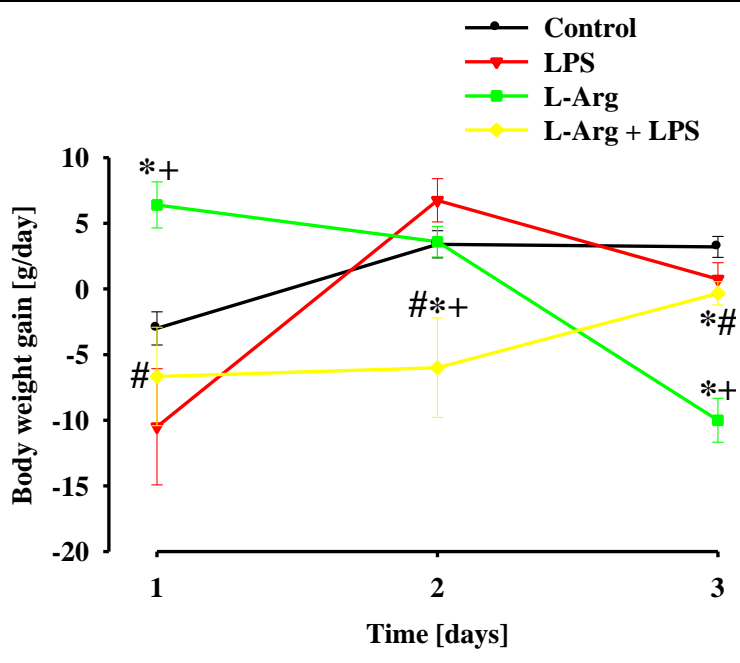

Fig. 4. Daily changes in body weight gain (g/day) of rats during days 1-3 of treatment. In: Control, LPS-treated (LPS), L-Arg-treated (L-Arg), and LArg-pretreated with LPS (L-Arg + LPS) groups. Data are presented as the mean \pm SEM $(n=3-5$ per treatment, independent t-test) $* \mathrm{P}<0.05$ vs. Control, $+\mathrm{P}<0.05$ vs. LPS, and \#P<0 0.05 vs. L-Arg groups.

\section{Thyroid function parameters}

\section{Serum triiodothyronine (T3) levels}

Fig. 5 gives the level of serum T3 $(\mathrm{ng} / \mathrm{mL})$ in the four treated groups at variable time points $(6,12,24$ and $72 \mathrm{~h})$ after last injection. Serum T3 levels did not change in LPS-treated group (1.29 \pm 0.09 , $1.20 \pm 0.08,1.29 \pm 0.17$ and $1.49 \pm 0.16$ ) at 6 , 12,24 and $72 \mathrm{~h}$ after last injection compared to the control group $(1.25 \pm 0.04,1.29 \pm 0.11$, $1.36 \pm 0.06$ and $1.42 \pm 0.10$ ). Serum T3 did not change in L-Arg-treated group $(1.51 \pm 0.01, \quad 1.26 \pm 0.09, \quad 1.32 \pm 0.22$ and $1.56 \pm 0.09$ ) at $6,12,24$ and $72 \mathrm{~h}$ after last injection compared to the control group $(1.25 \pm 0.04, \quad 1.29 \pm 0.11, \quad 1.36 \pm 0.06$ and $1.42 \pm 0.10)$.

In L-Arg + LPS-treated group, serum T3 concentration did not modify $(1.42 \pm 0.08,1.13 \pm 0.06$ and $1.28 \pm 0.02)$ at 6 , 12 and $72 \mathrm{~h}$ after last injection compared to the control group $(1.25 \pm 0.04,1.29 \pm 0.11$ and 1.42 \pm 0.10$)$. Serum T3 concentrations significantly decreased in the same group
$(1.04 \pm 0.04)$ at $24 \mathrm{~h}$ compared to the control group (1.36 \pm 0.06$)$.

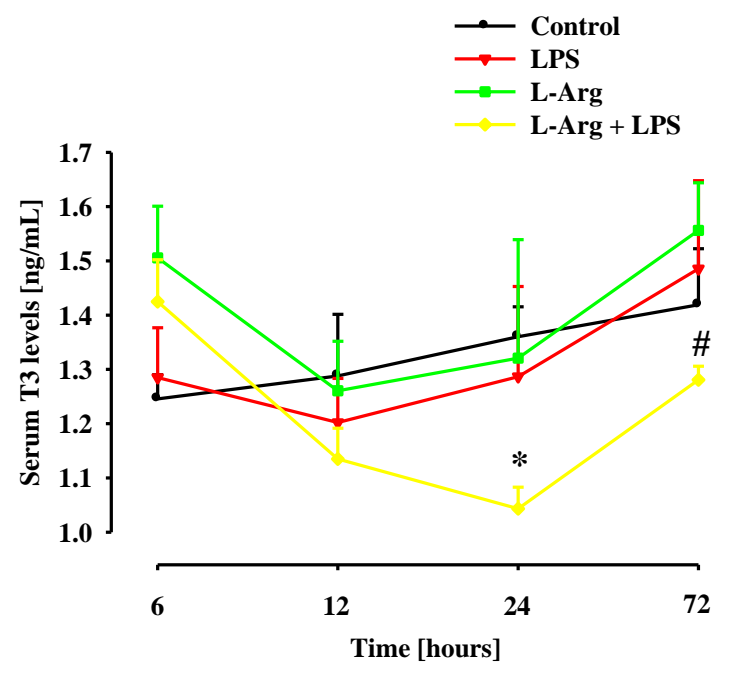

Fig. 5. The serum T3 levels after saline, LPS, LArg and L-Arg + LPS injection at different time points following last injection $(6,12,24$ and $72 \mathrm{~h})$. In: Control, LPS-treated (LPS), L-Arg-treated (LArg), and L-Arg-pretreated with LPS (L-Arg + LPS) groups. Data are presented as the mean \pm SEM ( $n=$ 3-5 per treatment, independent t-test) $* \mathrm{P}<0.05$ vs. Control and \#P< 0.05 vs. L-Arg groups.

\section{Serum triiodothyronine (T4) levels}

Fig. 6 shows the level of serum T4 $(\mu \mathrm{g} / \mathrm{dL})$ in the four treated groups at variable time points $(6,12,24$ and $72 \mathrm{~h})$ after last injection. In LPS-treated group, serum T4 levels did not modify (4.72 \pm 0.34 , $4.17 \pm 0.24,5.24 \pm 1.09$ and $4.67 \pm 0.28)$ at 6 , 12,24 and $72 \mathrm{~h}$ after last injection compared to the control group $(3.92 \pm 0.16,4.08 \pm 0.25$, $4.42 \pm 0.18$ and $5.57 \pm 1.08$ ). In L-Arg-treated group, serum $\mathrm{T} 4$ significantly increased $(5.74 \pm 0.57)$ at $6 \mathrm{~h}$ after last injection compared to the control group (3.92 \pm 0.16$)$ which recovered $(4.26 \pm 0.10,5.61 \pm 1.00$ and $4.39 \pm 0.18)$ at 12,24 and $72 \mathrm{~h}$ and reached almost control values $(4.08 \pm 0.25$ and $4.42 \pm 0.18$ and 5.57 \pm 1.08$)$. In L-Arg + LPStreated group, serum T4 levels did not change $(4.39 \pm 0.25,3.93 \pm 0.14,4.0 \pm 0.27$ and $3.71 \pm 0.12$ ) at $6,12,24$ and $72 \mathrm{~h}$ after last injection compared to the control group $(3.92 \pm 0.16, \quad 4.08 \pm 0.25, \quad 4.42 \pm 0.18$ and 


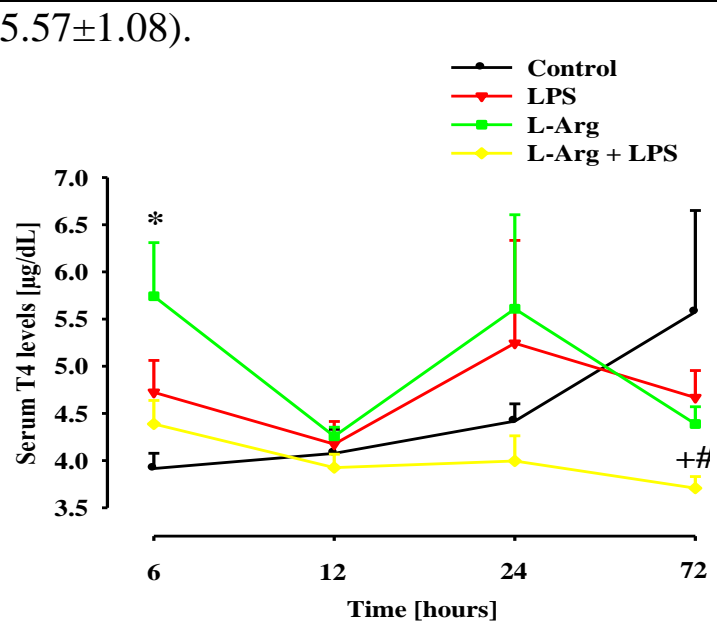

Fig. 6. The serum T4 levels after saline, LPS, LArg and L-Arg + LPS injection at different time points following last injection $(6,12,24$ and $72 \mathrm{~h})$. In: Control, LPS-treated (LPS), L-Arg-treated (LArg), and L-Arg-pretreated with LPS (L-Arg + LPS) groups. Data are presented as the mean $\pm \operatorname{SEM}(\mathrm{n}=$ 3-5 per treatment, independent t-test) $* \mathrm{P}<0.05$ vs. Control, $+\mathrm{P}<0.05$ vs. LPS, and \#P< 0.05 vs. L-Arg groups.

\section{Serum thyroid-stimulating hormone (TSH) levels}

Fig. 7 presents the levels of serum TSH $(\mu \mathrm{IU} / \mathrm{mL})$ in the four treated groups at variable time points $(6,12,24$ and $72 \mathrm{~h})$ after last injection.

In LPS-treated group, serum TSH levels were not altered $(0.18 \pm 0.01$, $0.18 \pm 0.01,0.17 \pm 0.01$ and $0.23 \pm 0.03$ ) at 6 , 12,24 and $72 \mathrm{~h}$ after last injection compared to the control group $(0.17 \pm 0.00,0.18 \pm 0.01$, $0.17 \pm 0.01$ and $0.22 \pm 0.03$ ).

Serum TSH levels did not change in LArg-treated group $(0.17 \pm 0.00,0.18 \pm 0.01$, $0.18 \pm 0.02$ and $0.16 \pm 0.00$ ) at $6,12,24$ and $72 \mathrm{~h}$ after last injection compared to the control group $(0.17 \pm 0.00, \quad 0.18 \pm 0.01$, $0.17 \pm 0.01$ and $0.22 \pm 0.03$ ).

In L-Arg + LPS-treated group, there was no change of serum TSH $(0.17 \pm 0.01$,
$0.16 \pm 0.00,0.17 \pm 0.00$ and $0.22 \pm 0.06)$ at 6 , 12,24 and $72 \mathrm{~h}$ after last injection compared to the control group $(0.17 \pm 0.00,0.18 \pm 0.01$, $0.17 \pm 0.01$ and $0.22 \pm 0.03)$.

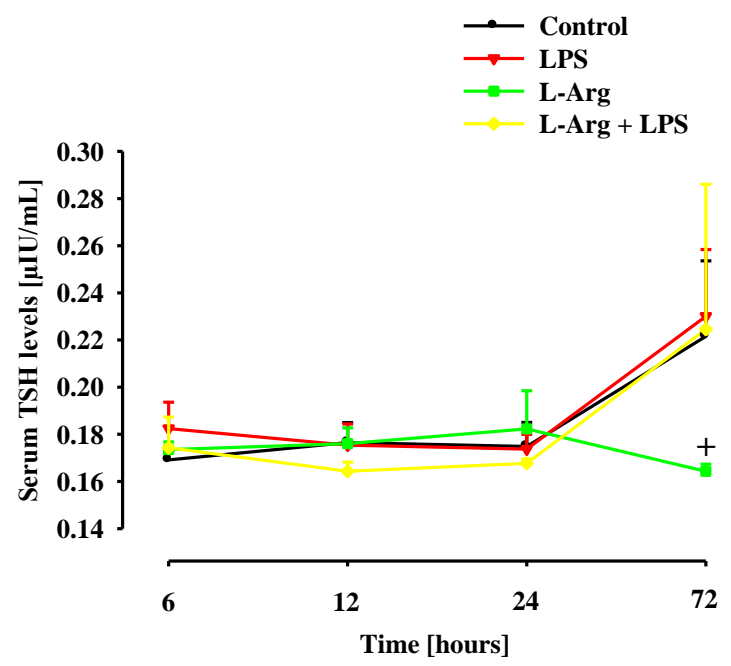

Fig. 7. The Serum TSH level after LPS, L-Arg, and L-Arg + LPS injection at different time points following last injection $(6,12,24$, and $72 \mathrm{~h})$. In: Control, LPS-treated (LPS), L-Arg-treated (LArg), and L-Arg-pretreated with LPS (L-Arg + LPS) groups. Data are presented as the mean $\pm \operatorname{SEM}(n=$ 3-5 per treatment, independent t-test $)+\mathrm{P}<0.05$ vs. LPS group.

\section{Histopathological findings}

The thyroid gland samples were collected 6, 12, 24 and $72 \mathrm{~h}($ each, $\mathrm{n}=5)$ after the last injection and immediately processed for histopathological examination under a light microscope. The microscopical examination of control group after saline injection at different time point, showed normal morphological features of thyroid gland including thyroid lobules consisted of follicles lined by cuboidal to columnar cells and contains lumen filled with colloid. Inter-follicular cells or C-cells are in the form of cluster or group of cells in between the follicles (Fig. 8 A-D). 


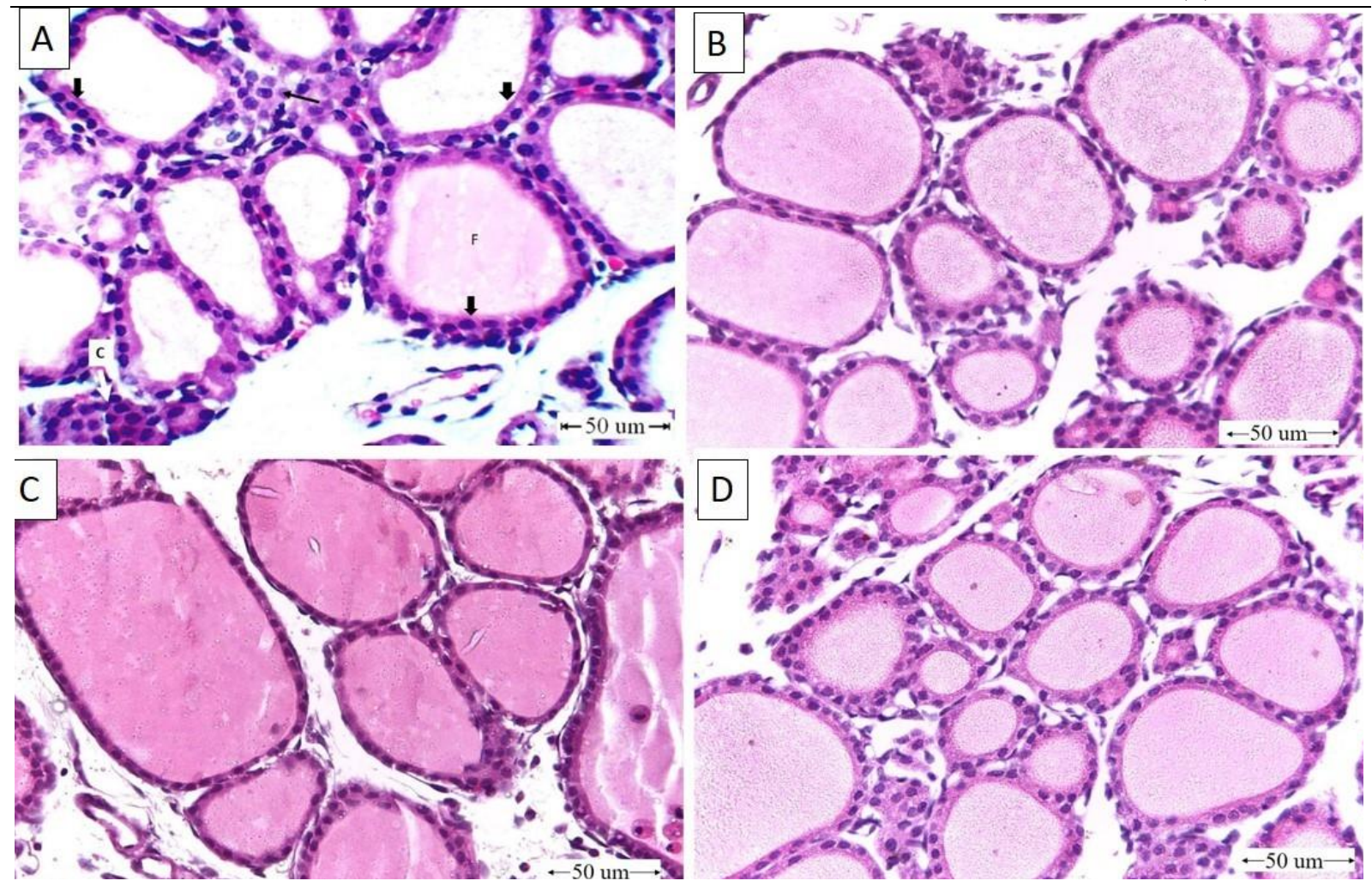

Fig. 8. A photomicrograph of rat thyroid tissues of the group I (Control). Thyroid sections from saline-injected rats pretreated with saline at 6 (A), 12 (B), 24 (C) and 72 (D) h after saline treatment showing normal morphological features of thyroid follicles lined by simple cuboidal epithelium (head black arrow) and filled with colloid, parafollicular cells (C-cells), and interfollicular tissues (black arrow). (H\&E, 400X).

After $6 \mathrm{~h}$, rats injected IP with LPS alone in a dose of $1 \mathrm{mg} / \mathrm{kg}$ showed dilatation of the follicles, which lined with flat epithelium and presence of few inflammatory cellular reactions in the interfollicular tissue was observed (Fig. 9A). Histopathological findings of thyroid gland obtained $12 \mathrm{~h}$ after LPS injection characterized by hyperemia of capillaries, desquamation of the follicular epithelium and depletion of its colloid, and presence of inflammatory cells intermingled with the desquamated epithelium inside the lumen (Fig. 9B).
Moreover, these pathological findings $24 \mathrm{~h}$ after LPS injection showed severe necrosis of the thyroid follicles with heavy accumulation of inflammatory cells in both the follicular lumen and inter-follicular tissue (Figs. 9C). Histopathological findings of thyroid gland obtained $72 \mathrm{~h}$ after LPS injection characterized by dilatation and less severe necrosis of the follicles. Moreover, prominent accumulation of lymphocytes and histocytes in the follicular lumen were observed (Fig. 9D). Thyroid gland of L-Arg-treated rats at different time 
points showed normal histological structure

D).

similar to that of control group (Fig. 10 A-

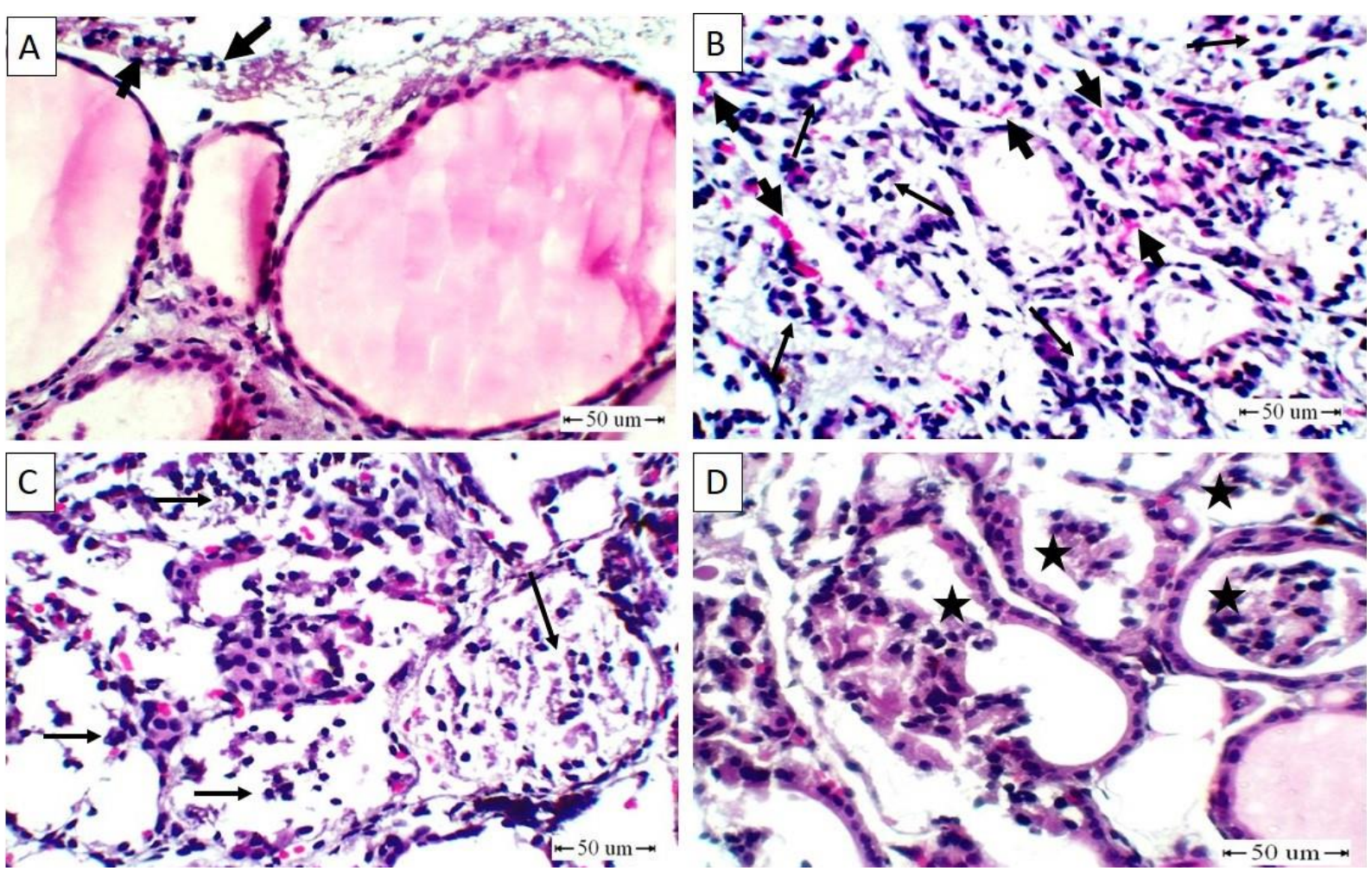

Fig. 9. A photomicrograph of rat thyroid tissues of the group II (LPS). (A): Thyroid sections from LPS-injected rats pretreated with saline at $6 \mathrm{~h}$ after LPS injection showing dilated follicles lined with flat epithelium cells and few inflammatory cellular reactions (black arrow). (B): At $12 \mathrm{~h}$ post LPS injection, sections showing hyperemia of capillaries (head arrow), desquamation of the follicular epithelium and depletion of its colloid, and presence of inflammatory cells intermingled with the desquamated epithelium (arrow). (C): At $24 \mathrm{~h}$ post LPS injection, sections showing severe necrosis of the thyroid follicles with heavy accumulation of inflammatory cells in both the follicular lumen and inter-follicular tissue (arrow). (D): At $72 \mathrm{~h}$ post-injection, sections showing prominent accumulation of lymphocytes and histocytes in the follicular lumen (star). (H\&E, 400X). 

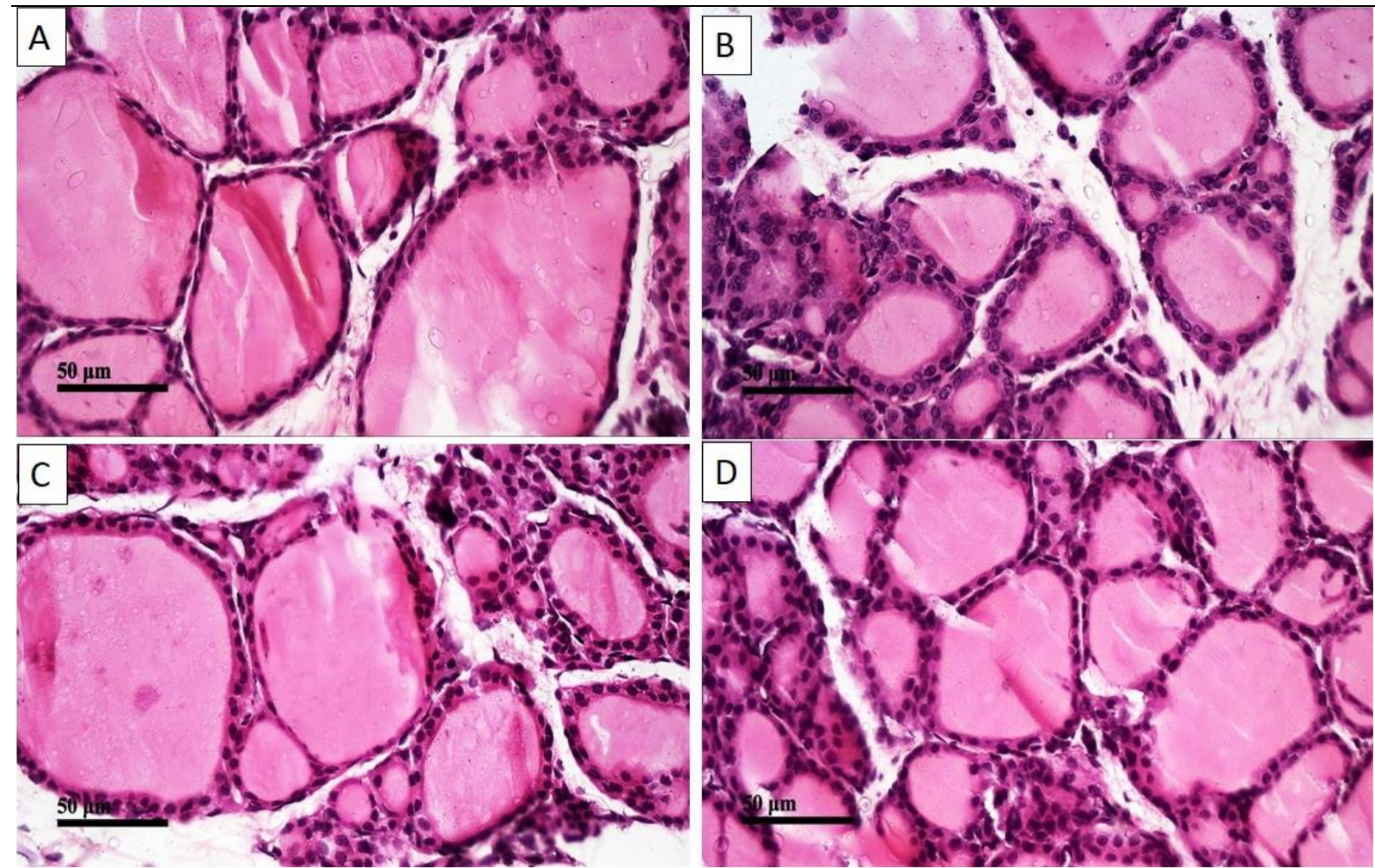

Fig. 10. A photomicrograph of rat thyroid tissues of the group III (L-Arg). Thyroid sections from saline-injected rats pretreated with L-Arg at 6 (A), 12 (B), 24 (C), and 72 (D) h after saline treatment showing normal morphological features of thyroid follicles as control group. (H\&E, 400X).

Regarding to injection of L-Arg for 7 consecutive days intraperitoneal followed by single dose of lipopolysaccharide, Histopathological examination $6 \mathrm{~h}$ after last injection, showed dilated follicles lined with flat epithelium and less inter-follicular inflammatory cellular reaction (Fig. 11A). Improvement of the thyroid gland tissues were noticed $12 \mathrm{~h}$ after injection and this was evidenced by healthy follicles lined with cuboidal epithelium (less active) and few inter-follicular inflammatory cellular reactions (Fig. 11B). Also, healthy follicles lined with flat epithelium were observed 24 $\mathrm{h}$ after L-Arg + LPS injection (Fig. 11C). In the same group, Histopathological examination $72 \mathrm{~h}$ after last injection, showed healthy follicles lined with flat epithelium and less accumulation of inflammatory cells in the follicular lumen (Fig. 11D). 


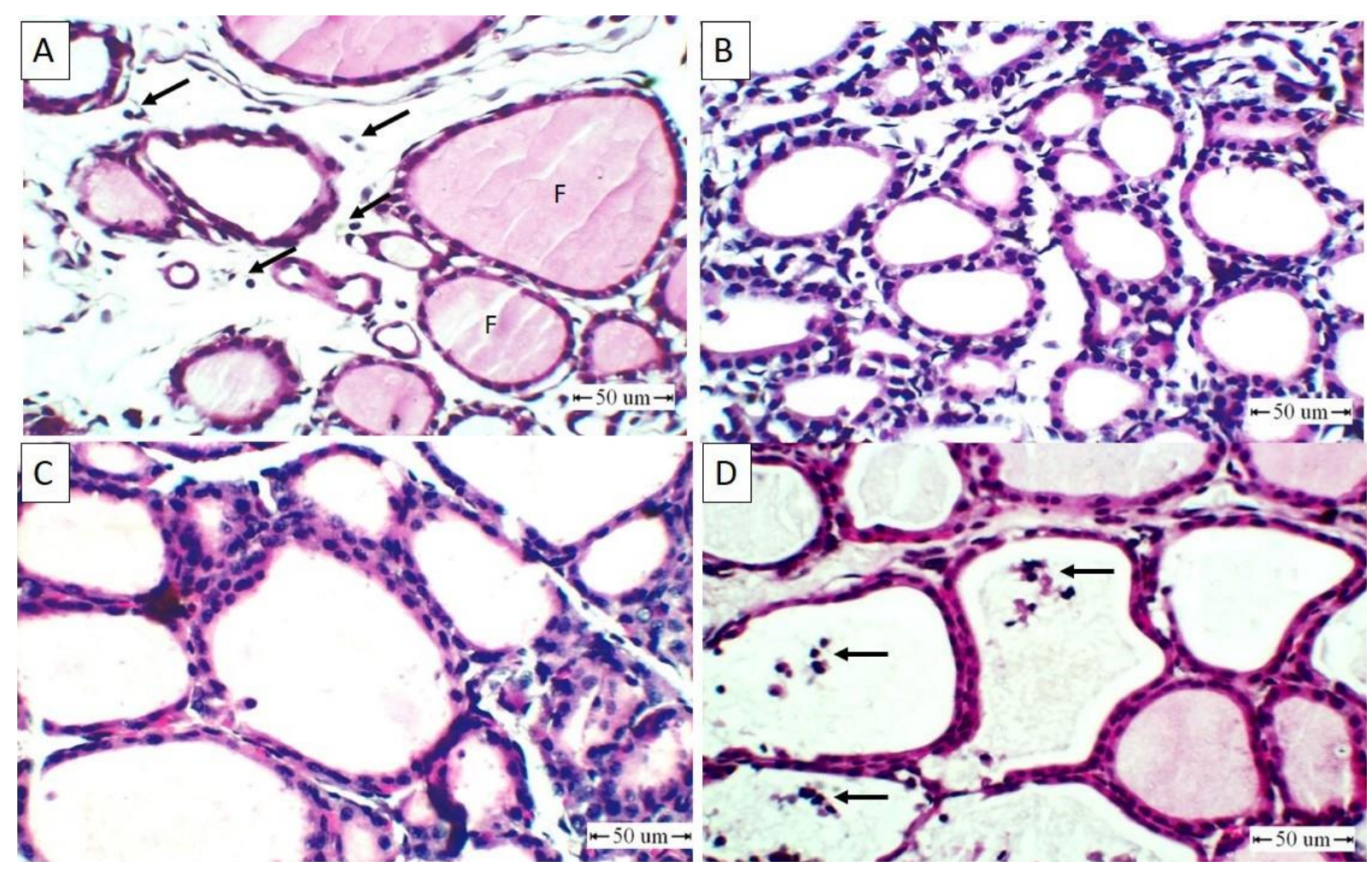

Fig. 11. A photomicrograph of rat thyroid tissues of the group IV (L-Arg + LPS). (A): Thyroid sections from LPS-injected rats pretreated with L-Arg at 6 after LPS injection showing dilated follicles (F) lined with flat epithelium and less inter-follicular inflammatory cellular reaction (arrow). (B): At $12 \mathrm{~h}$ post LPS injection, sections showing healthy follicles lined with cuboidal epithelium (less active) and few interfollicular inflammatory cellular reaction. (C): At $24 \mathrm{~h}$ post LPS injection, sections showing healthy follicles lined with flat epithelium. (D): At 72 $\mathrm{h}$ post LPS injection, sections showing healthy follicles lined with flat epithelium and less accumulation of inflammatory cells in the follicular lumen (arrow). (H\&E, 400X).

\section{DISCUSSION}

The aim of the current study was to clarify the effects of L-arginine (L-Arg) supplementation on the thyroid gland function in an in vivo model of endotoxemia. Therefore, A single intraperitoneal dose of bacterial endotoxin (lipopolysaccharide (LPS)) $(1 \mathrm{mg} / \mathrm{kg}$ body weight $(\mathrm{BW})$ ) was used to induce a rat model of Endotoxemia (Arab et al., 2020). In addition, this study was done to investigate the effects of these treatments on the appetite, survival rate, and growth performance of rats.
In the present study, a single IP injection of LPS at a dose $(1 \mathrm{mg} / \mathrm{kg} \mathrm{BW})$ induced acute systemic inflammation and sepsis characterized by fever, shivering, reduced activity, ruffled fur, anorexia and lethargy. The survival rate of LPS group were $90 \%$ at 3 days after LPS injection. Previous studies indicated that bacterial infection increases the risk of death (Kell and Pretorius, 2015; Chou et al., 2020). Severe sepsis is manifested by tachycardia, tachypnea, multiple organ dysfunction, and death (Kilár et al., 2013). On the other hand, no mortalities were recorded in control and L-Arg-treated alone groups. IP injection of $\mathrm{L}-\mathrm{Arg}$ at a dose $(10 \mathrm{mg} / \mathrm{kg} \mathrm{BW}, \mathrm{IP})$ for 7 
consecutive days and followed by a single dose of LPS resulted in a $5 \%$ decrease of survival rate at 12 hours (h) after LPS injection but reached a peak (15\%) at 3 days when compared with LPS alone treated rats. High concentration of nitric oxide (NO) plays an important role in regulating the inflammatory responses during bacterial infection (Tripathi, 2007; Wink et al., 2011) leading to hypotension and myocardial dysfunction ending with endotoxic shock and death (Heyland et al., 2001)

The main findings of this study were that food intake of LPS-treated group significantly decreased one day after the last injection, but this effect was transient, and the appetite recovered to normal levels within 2-3 days. These data clarified that LPS induces acute inflammation and anorexia in rats. In fact, it has been reported that administration of LPS induces acute inflammation, sickness behavior, and hypophagia in rats (Konsman et al., 2002; Embark, 2017). The proinflammatory cytokines produced by LPS stimulation, can cross the blood-brain barrier and cause sickness behavior and Hypophagia (Konsman, 2016; Embark, 2017). LPS induced fever and anorexia through Interleukin-1 $\beta$ (IL-1 $\beta$ ) (Luheshi et al., 1996; Layé et al., 2000).

However, food consumption of L-Arg group significantly increased one day after last injection then markedly decreased within 2-3 days after the last injection. LArg increase appetite through NO pathway via stimulation of ghrelin, orexin or neuropeptide $\mathrm{Y}$ to activate arcuate nucleus of hypothalamus (Wang et al., 2014). On the other hand, L-Arg pretreatment for 7 consecutive days followed by a single dose of LPS induced significant decrease of food intake 1-2days after LPS injection compared to LPS alone treated group and returned to normal values 3 days after the last injection. Together, our data indicates that L-Arg-NO pathway enhances the induction of acute inflammation and sickness behavior induced by LPS.

Injection of LPS induced no change of water intake on the 1st day after last injection. However, injection of L-Arg prior to LPS injection significantly reduced water intake on the 2nd day after LPS injection. LPS induced sickness behavior in experimental animals which characterized by lethargy, anorexia, and hyperthermia and reduced water intake. Furthermore, LPS induced kidney injury which associated with reduction of sodium excretion leading to dehydration and reduced water intake (Schmidt et al., 2007). The finding of this study clarified that L-Arg supplementation potentiates LPS-induced inhibition of water intake in rats.

In the present experimental rat model, body weight gain of rats in LPS group significantly decreased one day after last injection and returned to normal levels within 2-3 days. However, body weight gain of rats in L-Arg + LPS group significantly decreased on the 2nd day after LPS injection. Surprisingly, administration of L-Arg alone into the rats resulted in a significant decrease in body weight gain within 3 days of last injection. Reduction of efficiency of feed utilization were mediated by shifting of nutrients away from the growth process toward immune system function leading to reduction of body weight gain (Daiwen et al., 2008). Administration of LPS significantly increased adrenocorticotropic hormone $(\mathrm{ACTH})$ and corticosterone concentration 
few hours after LPS injection resulting in reduction of food consumption, metabolic disturbance and weight loss (Bison et al., 2008). Inhibition of L-Arg-NO pathway indicated that NO participates in LPSinduced body weight loss.

In the present study (Fig. 9), a single IP injection of LPS at a dose $(1 \mathrm{mg} / \mathrm{kg} \mathrm{BW})$ induced the typical changes of acute inflammation of thyroid gland. The alteration was manifested by desquamation of the epithelial lining the thyroid follicles. Vascular and cellular changes of the inflammatory process were expressed by hyperemia of capillaries and lymphoid cells in both the follicular lumen and interfollicular tissue. These changes were increased gradually from $6 \mathrm{~h}$ up to $72 \mathrm{~h}$. The most noticeable changes were observed at $12,24 \mathrm{~h}$ post-injection. These results indeed proved that LPS induce typical acute thyroiditis in rats. Concurrent with these pathological changes, altered physiological functions occurred such as decreased levels of $\mathrm{T} 3$ and $\mathrm{T} 4$ concentration in the circulation (Fig. 5-6). Results are in agreement with that of Zaccone et al., (2003) whose found that LPS induces acute thyroiditis. In addition, Boelen et al., (1995) reported that sub lethal dose of LPS causes reduction of serum T3 and T4 levels $4 \mathrm{~h}$ after LPS treatment and serum TSH did not changed resulting in sick euthyroid syndrome.

In accordance with the present results, previous studies evidenced that LPS down regulates the thyroid hormones levels either directly by reducing the secretion of thyroid follicular cells or indirectly by reducing TSH secretion from the pituitary gland. LPS affects several phases of Thyroid hormonogenesis. LPS stimulates synthesis and exocytosis of thyroglobulin into the follicular lumen then inhibits its resorption leading to reduction of serum $\mathrm{T} 3$ and $\mathrm{T} 4$ concentration (Iaglova and Berezov, 2010).

Experiment (Fig. 11) showed that LArg pretreatment has positive effect on LPS-induced thyroiditis. Since administration of L-Arg (10 mg.kg BW) for 7 consecutive days prior to the single IP dose of LPS resulted in remarkable decrease of the inflammatory changes observed. This was expressed by restoring the membrane integrity of the thyroid follicles, minimizing the accumulation of inflammatory cellular reaction in the follicular lumen, inter-follicular tissue, and the adipose tissue surrounding the follicles, as well as marked relaxation of the blood vessels, suggesting that L-Arg acts as antiinflammatory agent.

L-Arg pretreatment protects against LPS-induced thyroiditis in spite of reduction of serum T3, T4 levels compared to LPS treated group. L-Arg + LPS treated group associated with high NO production and thus could be related to reduction of serum T3, T4 levels.

\section{CONCLUSION}

The present study demonstrates that lipopolysaccharide (LPS) induced acute thyroiditis in adult male rats within 6 hours (h) after LPS injection. Pretreatment of Larginine (L-Arg) in LPS injected rats restored the adverse effects of LPS on thyroid gland and protected against acute thyroiditis. However, pretreatment of Larginine induced central hypothyroidism by reduction of serum $\mathrm{T} 3$ and $\mathrm{T} 4$ levels. We proposed that L-Arg-NO pathway was responsible for the protective effect of $\mathrm{L}$ - 
Arg. The underlying mechanism should be further investigated.

\section{CONFLICT OF INTEREST}

The authors declare that there are no conflicts of interest regarding publication of this article.

\section{ACKNOWLEDGEMENT}

The authors gratefully acknowledge all members and professors of the Department of Animal Physiology, Faculty of Veterinary Medicine, South Valley University, Qena, Egypt, and of the Animal Physiology Department, Faculty of Veterinary Medicine, Aswan University, Aswan, Egypt, for their constant encouragement and kind help.

\section{FINANCIAL SUPPORT}

This work was supported by grant No. 2505 from the Science and Technology Development Fund (STDF), Egypt.

\section{REFERENCES}

Akira S, Uematsu S, Takeuchi O (2006). Pathogen recognition and innate Immunity. Cell, 124(4):783-801.

Arab Z, Hosseini M, Mashayekhi F, Anaeigoudari A (2020). Zataria multiflora extract reverses lipopolysaccharide-induced anxiety and depression behaviors in rats. Phytomed Avicenna journal of phytomedicine, 10(1): 78-88.

Bancroft, J, Gamble M (2002). Theory and practice of histological techniques. 5th London Edinburgh New York Philadelphia St. Louis Sydney. Toronto, PP 377-694.
Bison S, Carboni L, Arban R, Bate ST, Gerrard, Razzoli M (2008). Differential behavioral, physiological, and hormonal sensitivity to LPS challenge in rats. International Journal of Interferon, Cytokine and Mediator Research, 2009 (1): 1-13.

Boelen A, Platvoet-ter Schiphorst MC, Bakker O, Wiersinga WM (1995). The role of cytokines in the lipopolysaccharide-induced sick euthyroid syndrome in mice. The journal of endocrinology, 146(3):475-483.

Chen Y, Jin S, Teng X, Hu Z, Zhang Z, Qiu X, Tian D, Wu Y (2018). Hydrogen Sulfide Attenuates LPS-Induced Acute Kidney Injury by Inhibiting Inflammation and Oxidative Stress. Oxidative Medicine and Cellular Longevity, 6717212. PP 1-10.

Chou EH, Mann S, Hsu TC, Hsu WT, Liu CC, Bhakta T, Hassani DM, Lee CC. (2020). Incidence, trends, and outcomes of infection sites among hospitalizations of sepsis: A nationwide study. PLoS One, 15(1): $1-13$.

Daiwen C, Keying Z, Chunyan W (2008). Influences of lipopolysaccharideinduced immune challenge on performance and whole-body protein turnover in weanling pigs. Livestock Science, 113(2): 291-295.

Embark, HM (2017). L-arginine accentuates sickness behavior induced by lipopolysaccharides in 
male albino rats. Assiut Veterinary

Medical Journal, 63: 117-124.

Harris H (1900). On the rapid conversion of haematoxylin into haematein in staining reactions. Journal of Applied Microscopic Laboratory Methods, 3(3): 777-780.

Heyland DK, Novak F, Drover JW, Jain M, Su X, Suchner U (2001). Should immunonutrition become routine in critically ill patients? A systematic review of the evidence. Journal of the American Medical Association, 286(8): 944-953.

Huang H, Liu T, Rose JL, Stevens RL, Hoyt DG (2007). Sensitivity of mice to lipopolysaccharide is increased by a high saturated fat and cholesterol diet. Journal of inflammation (London, England), 4(1): 4-22.

Iaglova NV, Berezov TT (2010). Regulation of thyroid and pituitary functions by lipopolysaccharide. Biomeditsinshaia Khimiya, 56(2):179-86.

Kell DB, Pretorius E. (2015). On the translocation of bacteria and their lipopolysaccharides between blood and peripheral locations in chronic, inflammatory diseases: the central roles of LPS and LPS-induced cell death. Integrative Biology (Camb), 7(11): 1339-1377.

Kilár A, Dörnyei Á, Kocsis B (2013). Structural characterization of bacterial lipopolysaccharides with mass spectrometry and on- and offline separation techniques. Mass spectrometry reviews, 32 (2): 90117.

Konsman JP (2016). Immune-to-brain signaling and substrates of altered behavior during inflammation. Neuroimmunology.

Neuroinflammation, 3: 207-214.

Konsman JP, Parnet P, Dantzer R (2002). Cytokine-induced sickness behaviour: mechanisms and implications. Trends in neurosciences, 25(3): 154-159.

Kopincová J, Púzserová A, Bernátová I (2012). L-NAME in the cardiovascular system - nitric oxide synthase activator? Pharmacological reports, 64(3):511520.

Layé S, Gheusi G, Cremona S, Combe C, Kelley K, Dantzer R, Parnet P (2000). Endogenous brain IL-1 mediates LPS-induced anorexia and hypothalamic cytokine expression. American journal of physiology. Regulatory, integrative and comparative physiology, 279(1): R93-R98.

Luheshi G, Miller AJ, Brouwer S, Dascombe MJ, Rothwell NJ, Hopkins SJ (1996). Interleukin-1 receptor antagonist inhibits endotoxin fever and systemic interleukin- 6 induction in the rat. The American journal of physiology, 270(1 Pt 1): E91-E95.

Mammadov R, Suleyman B, Akturan S, Cimen FK, Kurt N, Suleyman Z, Malkoc I (2019). Effect of lutein on 
methotrexate-induced oxidative lung damage in rats: a biochemical and histopathological assessment. The Korean journal of internal medicine, 34(6):1279-1286.

McConell GK (2007). Effects of L-arginine supplementation on exercise metabolism. Current opinion in clinical nutrition and metabolic care, 10(1):46-51.

Moustafa MA, Ghareeb DA, Hafez EE, ElGamal B, El-Sadanii M (2015). Larginine down-regulated TNFAlpha gene in LPS induced inflammation in experimental rats. European journal of pharmaceutical, 2(5): 1-19.

Schmidt C, Höcherl K, Schweda F, Kurtz A, Bucher M (2007). Regulation of sodium transporters during severe inflammation. Journal of the American Society of Nephrology, 18(4): 1072-1083.
Tripathi P (2007). Nitric oxide and immune response. Indian journal of biochemistry \& biophysics, 44(5): 310-319.

Wang C, Hou SS, Huang W, Xu TS, Rong GH, Xie M (2014). Arginine affects appetite via nitric oxide in ducks. Poultry Science, 93(8): 2048-2053.

Wink DA, Hines HB, Cheng RY, Switzer CH, Flores-Santana W, Vitek MP, Ridnour LA, Colton CA. (2011). Nitric oxide and redox mechanisms in the immune response. Journal of Leukocyte Biology, 89(6): 873-891.

Zaccone P, Fehérvári Z, Cooke A (2003). Tumour necrosis factor-alpha is a fundamental cytokine in autoimmune thyroid disease induced by thyroglobulin and lipopolysaccharide in interleukin-12 p40 deficient C57BL/6 mice. Immunology, 108(1):50-54. 